\title{
Does Conflict Help or Hinder Creativity in Teams? An Examination of Conflict's Effects on Creative Processes and Creative Outcomes
}

\author{
Claus W. Langfred ${ }^{1} \&$ Neta Moye ${ }^{2}$ \\ ${ }^{1}$ School of Management, George Mason University, Virginia, USA \\ ${ }^{2}$ PDRI, Arlington, USA \\ Correspondence: Claus Langfred, School of Management, George Mason University, 4400 University Drive, \\ Fairfax, VA 22030, USA. Tel: 1-703-993-9662. E-mail: clangfre@gmu.edu
}

Received: February 27, 2014

Accepted: April 16, $2014 \quad$ Online Published: May 22, 2014

doi:10.5539/ijbm.v9n6p30

URL: http://dx.doi.org/10.5539/ijbm.v9n6p30

\begin{abstract}
We examine the relationship between conflict and creativity-relevant intra-group processes over time. More specifically, we explore whether task and relationship conflict have effects on the extent to which teams engage in information exchange and creative problem solving. We test these relationships with multiple waves of longitudinal data collected from 141 individuals across 35 project teams. We find that, replicated across multiple periods of time, task conflict does not have an effect on either information exchange or creative problem solving, but relationship conflict does. Furthermore, while relationship conflict undermines intra-group creative processes, only task conflict appears to affect the creativity of the group's final outcomes. Contrary to the view of conflict as functional and stimulating, the outcome effect of task conflict was negative.
\end{abstract}

Keywords: conflict, creativity, teams, information exchange, longitudinal

\section{Introduction}

Creativity matters to organizations, not only as a competitive advantage in terms of innovative strategies, novel approaches to markets or new product development and differentiation, but also in terms of improving internal processes in the organization and identifying efficiency and productivity gains. Despite the fact that creativity often emerges from team efforts in the organizational setting (West \& Farr, 1990), the majority of creativity research has focused on individual creativity (Shalley, Zhou, \& Oldham, 2004; Mumford, 2003). Recently, research in creativity has turned its focus to team creativity (Gilson \& Shalley, 2004; Taggar, 2002). While these studies have made significant contributions to our understanding of team creativity, two recent reviews of the literature (Shalley et al., 2004; Mumford, 2003) have revealed many unanswered questions remain. Among these unanswered questions is how intra-team conflictmay affect team creativity.

We focus our research question on the influence of intra-group conflict because of uncertainty and ambiguity in the conflict literature as to what effects it might have on creativity. While some perspectives on conflict suggest that it should be beneficial to creative team processes and outcomes (Jehn, 1995; Jehn \& Mannix, 2001), other perspectives suggest that it may have considerable negative effects (Carnevale \& Probst, 1998; DeDreu \& Weingart, 2003).

In our attempt to unravel and understand these effects, we follow the lead of Gilson and Shalley (2004) in considering team processes as the mechanisms that may be crucial in determining creativity outcomes. It has been suggested that the creativity literature in general could benefit from focusing on factors that lead individuals to engage in creative thinking processes in the first place, as opposed to the current focus on creative outcomes (Shalley et al., 2004). At the team level, a focus on how creative outcomes are derived means directing attention to team creative processes, which to date have remained largely unexplored. We agree with an increased focus on team processes, and believe it is a necessary step in the creativity literature in order to better understand how general team conditions or dynamics relate to creative outcomes. We also believe it is a necessary next step in trying to resolve the discrepant views of how conflict may relate to creativity in teams.

In this paper, we attempt to understand and resolve inconsistent theoretical predictions about the effects of intra-team conflict on team creativity outcomes. We do this by exploring the effects of both task and relationship conflict on two team creative-process related variables (the extent of information exchange; and the engagement 
in team creative problem solving), and ultimately on team creative outcomes, thus linking inputs, process and outputs in one model. We develop this model of how we expect conflict to influence these creative processes and outcomes by drawing from the literature on team conflict, creative problem solving, and individual creativity. In doing so, our findings will extend the very limited research on team creative processes (Gilson \& Shalley, 2004; Taggar, 2001). Ultimately, our findings will help to clarify conceptual and empirical inconsistencies with about the role of conflict, and whether it helps or hinders creativity in teams.

\section{Literature Review and Hypotheses}

Conflict has long been known to have the potential to significantly influence group process and performance (for a review, see De Dreu \& Weingart, 2003), and has been studied extensively (Peterson \& Befar, 2003), both as a causal variable, and as an outcome. Conflict is often divided into two types; task conflict and relationship conflict (Jehn, 1995), and sometimes categorized into the similar concepts of cognitive and affective conflict (Wall \& Nolan, 1986). Task conflict is defined as disagreement among group members about decisions, viewpoints, ideas and opinions (Simons \& Peterson, 2000) and can include controversy over the best way to achieve a group goal or objective (Devine, 1999). Relationship conflict is defined as the perception of interpersonal incompatibility and is often characterized by animosity, tension and annoyance among members (Simons \& Peterson, 2000). Much is known about the various factors that can contribute to conflict in teams as well as the effects that conflict has on team dynamics and processes (Jehn \& Bendersky, 2003). There are a variety of typologies of conflict as well as different perspectives on studying conflict in teams (Befar \& Thompson, in press).

There have been two opposing views as to the influence of conflict on team processes and team outcomes (DeDreu \& Weingart, 2003). Generally speaking, one perspective is that conflict is stressful, disruptive, and therefore, detrimental to most if not all team processes and outcomes (Carnevale \& Probst, 1998). The alternative perspective is that, depending on the type of conflict, it can be stimulating and functional (Jehn, 1995). Such functional effects are only expected to occur for task conflict, not relationship conflict. What makes task conflict functional, according to this view, is that disagreement stimulates discussion and debate and encourages information exchange, leading to more creative solutions and generally better performance for the team. While the findings from a recent meta-analysis by DeDreu and Weingart (2003) find more support for the view of conflict as stressful, disruptive and detrimental to team process and outcomes, the issue was not completely resolved, since the mediating mechanisms inferred by the view of conflict as functional were not directly tested.

Unfortunately, the issue of whether conflict is beneficial or detrimental to creativity also remains unresolved. The mechanisms by which conflict is believed to be potentially functional are highly related to creativity, as they involve processes like information exchange. Furthermore, the principal argument for the benefits of conflict implicates creativity as a primary mechanism for these effects. There have been only a few studies which have examined the effect of conflict on creativity-related outcomes, and none that have examined the effect of conflict on the mediating creative processes. Given the critical role that such processes can play in resolving the uncertainty surrounding the beneficial or detrimental effects of conflict, we have focused our study on the effect of conflict on team creative processes, in addition to creative outcomes.

Over the past two decades, researchers who study creativity in the organizational context have defined it as the development of ideas about products, processes, services or procedures that are novel and potentially useful to the organization (Shalley et al., 2004; Amabile, 1996). However, much of the research on creativity has focused on either outcomes or inputs, but rarely on the processes within the teams themselves. Creativity as a process shifts the focus from what is produced (a creative outcome) to the behaviors, activities, or process engaged in on the way to generating creative outcomes (Torrance, 1988). Creative processes, generally speaking, involve breaking perceptual and cognitive sets and trying new problem solving techniques. As Torrance (1988) has suggested, creative processes include many activities such as problem identification, searching for new or novel ways of doing things, and synthesizing, combining or recombining information or ideas into new or novel ones. Only one paper to date has conceptualized and operationalized team creative processes, but did not link them to outputs, exploring only antecedents (Gilson \& Shalley, 2004). We believe that understanding the effect of conflict on creativity requires separating the effects of process from outcomes, and exploring all the steps of the traditional "input-process-output" model.

As mentioned above, there seem to be two team creative-process related variables that are particularly relevant processes to successful team creative outcomes; information exchange and team creative problem solving. Information exchange captures the extent to which team members communicate factual, task relevant 
information to other group members (Henry, 1995; Stasser, 1992), including offering opinions, suggestions, ideas and information relevant to the task (Bales, 1951). Team creative problem solving is also defined primarily in behavioral terms, and refers to an approach to problem solving that reflects a general propensity among team members to use creative, not routine, ways of completing tasks and solving problems. This includes team members actively seeking out, and combining, ideas, as well as searching for alternatives and novel approaches. Essentially, team creative problem solving captures the processes that are assumed to be a necessary pre-condition for creative team outcomes (Kanter, 1988; Woodman, Sawyer, \& Griffin, 1993). Both of these process variables are critical, and both are likely to be influenced by conflict.

Thus, in this study we explore how task and relationship conflict affects two team process variables related to creativity - the degree of information exchange and team engagement in creative problem solving. We also explore how task and relationship conflict relate to the creativity of team outcomes, as mediated by the two creativity-related team process variables.

\subsection{Task Conflict and Team Process}

Despite traditional beliefs about the potential benefits of task conflict in particular circumstances, we expect that task conflict overall is likely to have a negative effect on information sharing in teams.

Task conflict has often been described as the "constructive" form of conflict (Jehn \& Mannix, 2001). Traditionally it has been argued that, in the context of a cognitively complex task, task conflict can stimulate discussion, information exchange, and ultimately divergent thinking (Amason, 1996), especially for complex tasks with non-standard solutions. The discussion of differences of opinions that follows the experience of task conflict is believed to lead to a synthesis of ideas (Jehn, 1995), which allows the group to arrive at a solution superior to one based on each individual's originally held perspective. However, while the benefits of enhanced discussion and debate that can result from low levels of task conflict are undoubtedly real (DeDreu \& Weingart, 2003), we believe that on average, negative effects of higher task conflict will dominate the specific benefits at low levels. Thus, while we are not dismissing the benefits that low levels of task conflict can have in particular settings (such as decision making tasks), we expect that on average, across different types of teams and tasks, the overall effect of task conflict on information sharing will be negative.

While DeDreu and Weingart (2003) did not specifically explore team processes, their meta-analysis demonstrated that task conflict generally had negative effects on performance and satisfaction in teams. These findings are consistent with an information-processing perspective on conflict (Carnevale \& Probst, 1998), by which higher levels of task conflict interfere with cognitive flexibility and creative thinking, and thus impede information processing. This argument strongly supports the notion of an overall negative relationship between task conflict and both information exchange, and creative problem solving in the team. (It is also worth noting that DeDreu and Weingart's (2003) findings also undermine much of the logic for the belief in general benefits of task conflict, suggesting that positive effects are not be as robust as was commonly believed).

The expectation of negative effects of task conflict on information sharing is also supported by the decision-making literature. Researchers in the area of group decision-making (specifically, brainstorming research) argue that task conflict should be reduced in order to create a context of openness to new ideas, spurring idea generation (Paulus, Brown, \& Ortega, 1999). The technique of brainstorming was derived from the belief that, during the stage at which ideas are being generated, conflict would undermine idea generation. This belief resulted from observations that individuals actually generate more ideas than groups, given the same task and time constraints. The explanation for this effect was believed to be twofold-that in a group setting, debate and criticism of ideas occurs, which undermines idea fluency by both production blocking (i.e. getting in the way of sharing additional ideas) and potentially generating evaluation apprehension among group members (i.e., creating reluctance and fear of negative reactions). To the extent team members suffer from evaluation apprehension, they will most likely self censor more, reducing the ideas they are willing to share. While these negative effects on the willingness to share information in group settings may be particularly strong as a result of relationship conflict, the fact that task conflict is about disagreement about ideas, viewpoints and opinions, means it is likely to still trigger these negative effects and resulting reluctance to share ideas and information-especially in the case of higher levels of task conflict. This is consistent with negative effects.

Thus, based on the arguments above, we expect that while low levels of task conflict may benefit information exchange in some teams and for some tasks, the overall effect on information exchange will be negative.

Hypothesis 1: Higher task conflict will result in lower levels of information exchange.

The logic for team creative problem solving is similar to that articulated for information exchange above, 
including DeDreu and Weingart's (2003) conclusions that task conflict interferes with information processing, harming cognitive flexibility and creative thinking within the team. While low levels of task conflict may result in benefits that can encourage creative problem solving for particular types of tasks, we believe that the overall effect will be negative, and therefore expect a negative relationship between task conflict and creative problem solving.

In addition, several researchers have noted that high levels of task conflict can result in tension (Jehn, 1994; Amason, 1996) and possibly avoidance, which would undermine collective creative problem solving in teams. In addition, it has been pointed out that high levels of task conflict not only can become very contentious (Amason, 1996), but can also result in negative emotional reactions (Yang \& Mossholder, 2004). As Amabile (1996) has pointed out, negative emotion reduces cognitive functioning and ultimately undermines the divergent thinking that is a necessary component of creative problem solving within the team. These considerations suggest the following similar hypothesis.

Hypothesis 2: Higher task conflict will result in lower levels of team creative problem solving.

\subsection{Relationship Conflict and Team Process}

We expect that relationship conflict will reduce levels of information exchange and team creative problem solving. These negative effects may occur through several mechanisms.

First, to the extent that team members perceive relationship conflict, they will reduce interactions with one another. Avoidance is one of the most common responses to conflict, and it often leads to team members wanting to isolate their activities from one another (Amason, 1996; Jehn, 1994). Li and Hambrick (2005) refer to this as "behavioral disintegration", which is a concept related to behavioral interdependence (Wageman, 2001), and describes the extent to which team members try to disengage from those with whom they experience conflict, and further limit their interactions (and dependence). Essentially the argument is that the more relationship conflict there is in a team, the more likely team members are to avoid one another, and reduce interactions. If interactions in a team are reduced, communication is reduced-and thus, by logical necessity, information exchange is reduced because the conduits of that information are being restricted. This suggests that relationship conflict will result in reduced information exchange.

This reduced opportunity for information exchange is exacerbated by the reluctance to share information, particularly novel information. Reluctance to share information can result from relationship conflict in two ways. First, while individuals are generally reluctant to share novel information in organizations (Amabile, 1996), this reluctance is heightened when others are perceived as being different than oneself. Since relationship conflict is the perception of personal differences among group members, it follows that greater relationship conflict will further reduce any willingness to share information. A second source of reluctance to share information harks back to the arguments of evaluation apprehension noted by research on the topic of brainstorming. Relationship conflict is likely to be experienced as criticism or at the very least as a negative consequence, which has already been linked to increased evaluation apprehension. As the literature on brainstorming suggests, increased evaluation apprehension reduces your willingness to share ideas or exchange information.

Whether the mechanism is less opportunity to exchange information due to behavioral disintegration, or less willingness to exchange information due to heightened perceptions of personal differences and related evaluation apprehension, we expect the following:

Hypothesis 3: Higher relationship conflict will result in lower information exchange.

Many of the same arguments will hold true for team creative problem solving in that opportunities for creative problem solving will decrease as team members limit their interactions as a result of relationship conflict. In addition, since relationship conflict often involves animosity, tension and annoyance among team members (Simons and Peterson, 2000), these negative emotions will further undermine creative problem solving as well. First, as noted by Amabile (1996), negative emotions limit cognitive functioning, which further limits the ability to be think divergently and to engage in the request search for variety that is associated with creative problem solving. In addition, following Amabile's (1996) intrinsic motivation principle of creativity, the negative emotions concomitant with relationship conflict will undermine the motivation to engage in creative problem solving. Whether the reasons are decreased opportunity, decreased ability, or decreased willingness, we predict the following:

Hypothesis 4: Higher relationship conflict will result in lower levels of team creative problem solving. 


\subsection{Creativity Outcomes}

Based on the creativity and innovation literature, we expect that both information exchange and team creative problem solving will have positive effects on overall creative outcomes at the team level.

With regard to information exchange, having ample information or ideas is an important prerequisite for generating creative outcomes. Following Simonton's (1999) theory regarding how creative outcomes are generated at the individual level, creative idea generation involves an iterative process of variation and selection. The generation of creative ideas in the early variation stage depends on both the number and the breadth of cognitive elements (bits of information, or ideas) available. More specifically, the more idea possibilities you will be able to generate the more and more varied the raw material you have to work with. This general concept of more and more varied information yielding more creative outcomes is consistent with Sternberg's (1988) theory of the creative process as well. We believe these same theoretical perspectives hold true at the group level. Therefore, if members within a team are more willing to share or exchange information and ideas, creative outcomes will be more likely. To the best of our knowledge, this relationship has not yet been tested empirically.

Hypothesis 5: Higher information sharing will result in team outcomes that are more creative.

The relationship between team creative outcomes and the extent to which a team engages in creative problem solving is very straightforward, and is expected to result in a positive relationship. The very definition of the construct of team creative problem solving is based on the behavioral processes that researchers believe will result in creative team outcomes (Kanter, 1988; Woodman, Sawyer, \& Griffin, 1993). Therefore, a high degree of team creative problem solving essentially means that the behavioral steps and processes that are necessary preconditions for creative team outcomes are in place within the team. Interestingly, while this is a clear prediction for a positive effect, it has not been empirically tested. Given the above implications, we expect that the more a team engages in creative problem solving, the more creative their team outcomes will be, suggesting the following hypothesis:

Hypothesis 6: Higher team creative problem solving will result in higher team creativity.

Finally, Hypotheses 5 and 6 logically imply an indirect (or mediated), effect of task and relationship conflict on team creativity outcomes - carried through the mechanisms of information exchange and team creative problem solving. In other words, since we predict that task conflict will have negative effects on information sharing and team creative problem solving (Hypotheses 1 and 2), and that relationship conflict will have similarly negative effects (Hypotheses 3 and 4), AND that both information exchange and team creative problem solving will affect team creativity, this implies an indirect effect of task and relationship conflict on team creativity. This suggests the following two overall summary hypotheses:

Hypothesis 7: Higher task conflict will result in lower team creativity.

Hypothesis 8: Higher relationship conflict will result in lower team creativity.

\section{Methods}

\subsection{Setting}

The participants comprised a cohort of MBA graduate students organized into self-managing teams at a private Midwestern university. Students were assigned into teams and worked in these teams for the next four months, across eight different required classes and a wide variety of tasks (including financial analyses, marketing projects, statistical problem sets, business case write-ups, presentations, and longer papers and projects), culminating in a week-long final case competition. The teams were self-managing, and had complete discretion in deciding how to carry out assignments, and were not formally evaluated on their processes or methods for carrying out assignments, only on the quality of their output. Students were placed into teams of four students each, based on criteria designed to maximize within-team heterogeneity (in terms of gender, nationality, educational background and work experience) as well as minimize between-team heterogeneity (i.e. to ensure the teams were as similar as possible in demographics to one another). Every team had both genders, at least two nationalities, and at least three different undergraduate majors. This provided a methodological control for some demographic variables (in that the even distribution reduced the need to include those variables as controls in the statistical analyses and further limit degrees of freedom). Data were collected in multiple waves during the semester, resulting in measures from weeks 3 and 6 , as well as in weeks 12 and 15 .

\subsection{Participants}

There were 141 participants across 35 teams. Overall (across the multiple waves), the individual response rate averaged $71.6 \%$, and the team response rate was $93.6 \%$ (teams were dropped from the analysis if less than half 
the team members responded in that particular wave). This yielded 33 teams in each wave of data collection, and 31 teams that were repeated across all waves. Of the respondents, $21.4 \%$ were female, and $78.6 \%$ were male. US citizens comprised $65.0 \%$ of the respondents, with the largest non-US contingents made up of Chinese, Indian, Japanese and Korean nationals. The average age was 28.9; the youngest was 23 and the oldest was 44 .

\subsection{Measures}

\subsubsection{Team Creativity}

This was measured by the team's performance on a final case competition. Expert raters (a minimum of six of them) judged the creativity of each team's solution and presentation of the same business problems. Raters witnessed each team's presentation and had the opportunity to question each team. The raters were university faculty, industry experts, former students, and communication specialists. Each rater assigned points on the creativity of the case analysis and of the recommendations. The measure is the average numerical rating of the expert raters. Thus, the creativity measure was the aggregation of the judgments of at least six different expert raters on a single-item measure of overall creativity.

The survey questionnaires given to the team members used multi-item scales, summarized below (Note 1).

\subsubsection{Task Conflict}

We used Jehn's (1995) 4-item scale for task conflict. The Cronbach alpha was .89 and the mean $\mathrm{r}_{\mathrm{wg}}$ was .72 . Items included "There are a lot of differences of opinion in my team" and "There is considerable disagreement in the team about the way to work".

\subsubsection{Relationship Conflict}

We used Jehn's (1995) 4-item scale for relationship conflict. The Cronbach alpha was .96 and the mean $\mathrm{r}_{\mathrm{wg}}$ was .79. Items included "There is a lot of personality conflicts in my team" and "There is a lot of friction among members in my team".

\subsubsection{Information Exchange}

This 3-item scale was based on Bunderson and Sutcliffe's (2002) scale. This scale is intended to measure the degree to which team members are sharing their expertise and knowledge with one another in order to complete the task and make decisions about important issues. The Cronbach alpha was .85 and the mean $r_{w g}$ was .74 . Items included "Members of my team freely provided their personal expertise and insight."

\subsubsection{Team Creative Problem Solving}

This 6-item scale was adapted from Gilson and Shalley (2004). The Cronbach alpha was .80 and the mean $\mathrm{r}_{\mathrm{wg}}$ was .70. Items included "My team searches for novel approaches not required at the time" and "My team is good at coming up with new ways of doing things".

\subsection{Analysis}

\subsubsection{Procedure}

In order to test the causal relationships predicted in our hypotheses, we used longitudinal data allowing us to test hypotheses with dependent variables measured later in time than independent variables. We used lagged multiple regression where the dependent variables at time $t$ was predicted by the independent variable(s) at time $\mathrm{t}-1$, as is recommended by Cohen and Cohen (1983), and a common method used for the analysis of longitudinal data (for a recent example, see Tekleab, Takeuchi \& Taylor, 2005). When using such a technique it is important to control for the dependent variable at time t-1 as well, which is often neglected in this type of longitudinal analysis. Other analytic techniques designed for the analysis of data over time, such as event history analysis (Allison, 1984) and multi-level growth models (Singer \& Willett, 2003) are not appropriate to our data or type of hypotheses.

In addition, multiple waves of data allowed us to test the team process hypotheses (hypotheses 1, 2, 3 and 4) at two different time periods, using distinct data. Thus, each of these hypotheses were tested in an early time period (weeks 3 to 6), and then re-tested for replication in a later time period (weeks 12 to 15). The hypotheses related to outcome variables were tested during the final time period since that is when the performance measure was collected. Because the number of teams to meet the inclusion criteria varied across waves of data collection, and not all of the same teams were represented in each wave, some analyses involved as few as 31 teams, and others involved as many as 33 teams. 


\subsubsection{Aggregation}

Exploring team-level constructs and relationships based on individual perceptual data necessitates aggregation (George \& James, 1993). To estimate the appropriateness of such aggregation, we used the $r_{w g}$ statistic (James, Demaree and Wolf, 1993), which is a measure of within-group inter-rater agreement.

\section{Results}

The $r_{\mathrm{wg}}$ scores confirmed the appropriateness of aggregation for task and relationship conflict, information exchange and team creative problem solving. The variance inflation factor (VIF) scores for each variable were below accepted thresholds, suggesting that multicollinearity was not a problem in the analyses. Tables $1 \mathrm{a}$ and $1 \mathrm{~b}$ provide means, standard deviations and correlations for both rounds of longitudinal data collected.

Table 1a. First round means, standard deviations, and intercorrelations

\begin{tabular}{llllll}
\hline & Mean & Std.Dev & (1) & (2) & (3) \\
\hline 1. Task conflict (w3) & 3.63 & 1.45 & & & \\
2. Relationship conflict (w3) & 2.97 & 1.57 & $.81^{* *}$ & & \\
3. Information exchange (w6) & 7.33 & 1.23 & $-.34^{*}$ & $-.53^{* *}$ & \\
4. Creative problem solving (w6) & 5.91 & 0.70 & $-.48^{* *}$ & $-.64^{* *}$ & $.88^{* *}$ \\
\hline
\end{tabular}

Note. *-.05 Significance **-.01 Significance.

Table $1 \mathrm{~b}$. Second round means, standard deviations, and intercorrelations

\begin{tabular}{lllllll}
\hline & Mean & Std.Dev. & $(1)$ & (2) & (3) & $(4)$ \\
\hline 1. Task conflict (w12) & 3.62 & 1.32 & & & & \\
2. Relationship conflict (w12) & 3.36 & 1.81 & $.86^{* *}$ & & & \\
3. Information exchange (w15) & 7.40 & 1.22 & $-.58^{* *}$ & $-.75^{* *}$ & \\
4. Creative problem solving (w15) & 6.27 & 1.49 & $-.53^{* *}$ & $-.62^{*}$ & $.48^{* *}$ \\
5. Team creativity outcome & 4.35 & 0.81 & $-.42^{*}$ & -.27 & $.15^{* *}$ & .15 \\
\hline Note. ${ }^{*}$ - .05 Significance ** -.01 Significance. & & & & & &
\end{tabular}

Hypothesis 1 predicted that task conflict would have a negative effect on information exchange in the team. Results illustrated in models 1 and 3 of Tables $2 a$ and $2 b$ show that when controlling for information exchange measured earlier, there was no significant effect of task conflict on information exchange - in either the first round (week 3 to week 6 ) or the later round (week 12 to week 15). Thus, there was no support for Hypothesis 1.

Hypothesis 2 predicted that task conflict would have a negative effect on team creative problem solving. Results illustrated in models 1 and 3 of Tables $3 a$ and $3 b$ show that when controlling for prior team creative problem solving measured, there was no significant effect of task conflict on team creative problem solving, in either the first round (week 3 to week 6) or the later round (week 12 to week 15). Thus, there is no support for Hypothesis 2.

Table 2a. First round lagged regression: information exchange as dependent variable

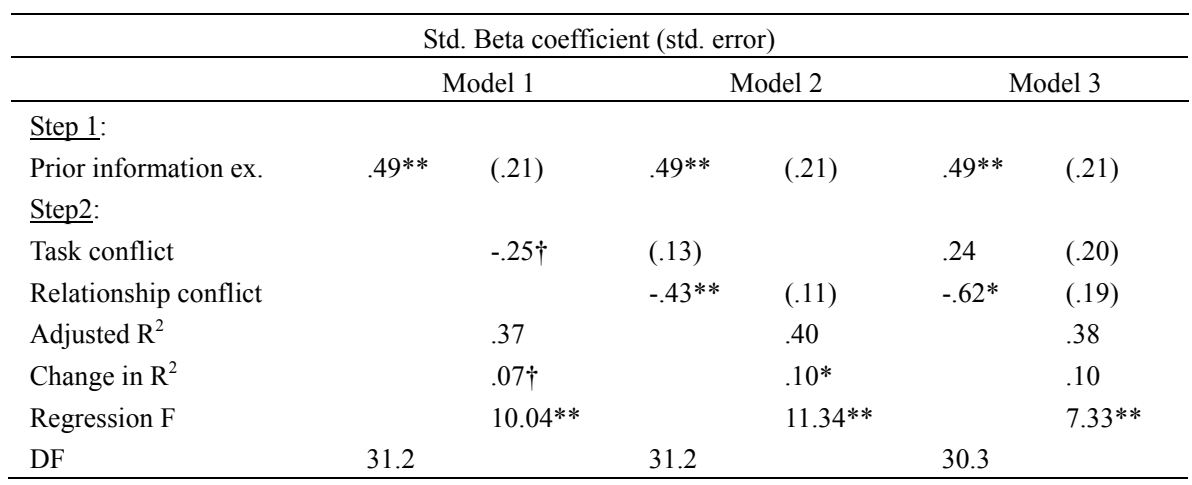

Note. $\dagger-\mathrm{p}<0.10 *-\mathrm{p}<0.05 * *-\mathrm{p}<0.01$. 
Table $2 b$. Second round lagged regression: information exchange as dependent variable

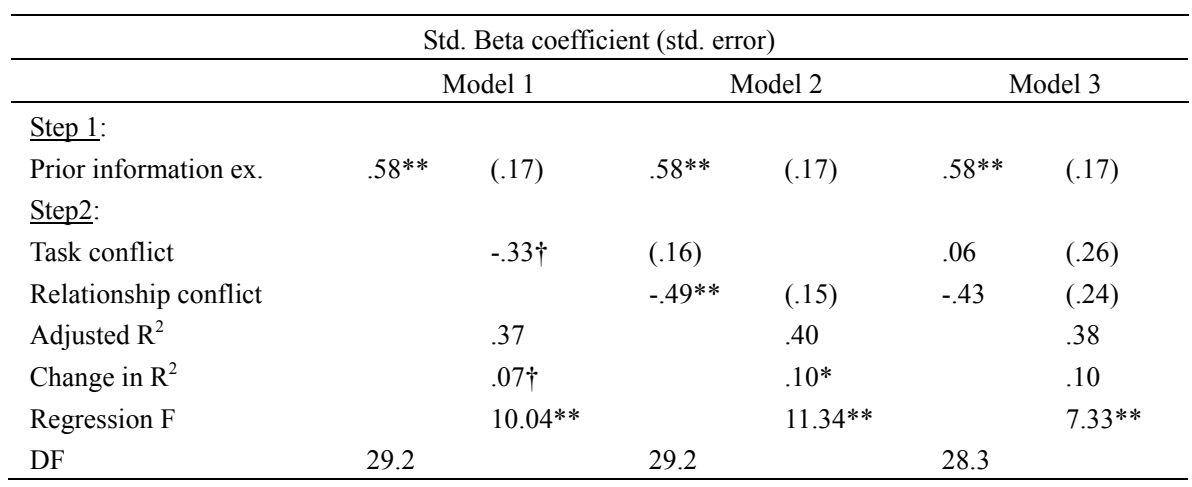

Note. $\uparrow-\mathrm{p}<0.10 *-\mathrm{p}<0.05 * *-\mathrm{p}<0.01$.

Table 3a. First round lagged regression: team creative problem solving as dependent variable

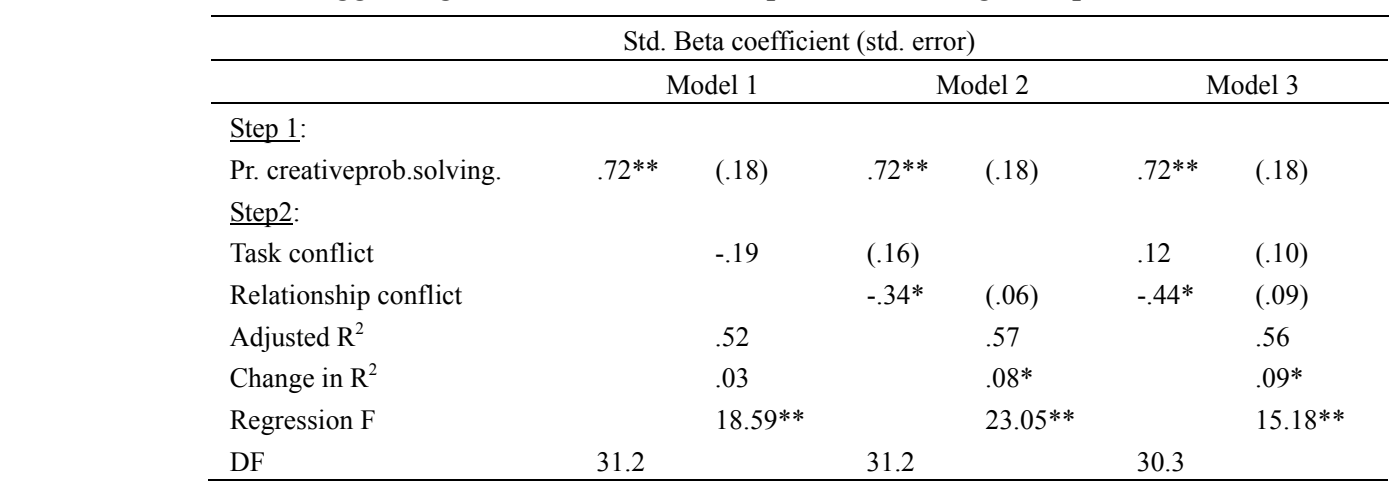

Note. $\uparrow-\mathrm{p}<0.10 *-\mathrm{p}<0.05 * *-\mathrm{p}<0.01$.

Table $3 \mathrm{~b}$. Second round lagged regression: team creative problem solving as dependent variable

\begin{tabular}{|c|c|c|c|c|c|c|}
\hline \multicolumn{7}{|c|}{ Std. Beta coefficient (std. error) } \\
\hline & \multicolumn{2}{|c|}{ Model 1} & \multicolumn{2}{|c|}{ Model 2} & \multicolumn{2}{|c|}{ Model 3} \\
\hline $\begin{array}{l}\text { Pr. creativeprob.solving. } \\
\text { Step2: }\end{array}$ & $.70 * *$ & $(.26)$ & $.70^{* *}$ & $(.26)$ & $.70 * *$ & $(.26)$ \\
\hline Task conflict & & $-.26 \dagger$ & $(.07)$ & & -.24 & $(.29)$ \\
\hline Relationship conflict & & & -.27 & (.14) & -.03 & $(.25)$ \\
\hline Adjusted $\mathrm{R}^{2}$ & & .52 & & .50 & & .50 \\
\hline Change in $\mathrm{R}^{2}$ & & $.06 \dagger$ & & .04 & & $.06 \dagger$ \\
\hline Regression F & & $17.57 * *$ & & $16.65^{* *}$ & & $11.32 * *$ \\
\hline DF & 29.2 & & 29.2 & & 28.3 & \\
\hline
\end{tabular}

Note. $\dagger-\mathrm{p}<0.10 *-\mathrm{p}<0.05 * *-\mathrm{p}<0.01$.

Hypothesis 3 predicted that relationship conflict would have a negative effect on information exchange in the team. Results illustrated in models 2 and 3 of Tables $2 a$ and $2 b$ show that when controlling for information exchange measured earlier, there appeared to be a significant negative effect of relationship conflict on information exchange - in both the first round and the later round. Thus, there was strong support for Hypothesis 3.

Hypothesis 4 predicted that relationship conflict would have a negative effect on team creative problem solving. Results illustrated in models 2 and 3 of Tables $3 \mathrm{a}$ and $3 \mathrm{~b}$ show that when controlling for team creative problem solving measured earlier, there was a significant negative effect of relationship conflict on team creative problem solving in the first round but not in the later round. Thus, there was support for Hypothesis 4 in the early round, but it could not be replicated in the later round. 
Table 4. Regression: team creativity as dependent variable

\begin{tabular}{|c|c|c|c|c|c|c|}
\hline \multicolumn{7}{|c|}{ Std. Beta coefficient (std. error) } \\
\hline & \multicolumn{2}{|c|}{ Model 1} & \multicolumn{2}{|c|}{ Model 2} & \multicolumn{2}{|c|}{ Model 3} \\
\hline Information exchange & .24 & $(.12)$ & & & $.44 \dagger$ & $(.19)$ \\
\hline Creative problem solving & & & .16 & $(.19)$ & -.38 & $(.30)$ \\
\hline Adjusted $\mathrm{R}^{2}$ & & .03 & & .00 & & .024 \\
\hline Regression F & & 1.85 & & .86 & & 1.39 \\
\hline DF & 31.1 & & 31.1 & & 30.2 & \\
\hline
\end{tabular}

Note. $\dagger-\mathrm{p}<0.10 *-\mathrm{p}<0.05 * *-\mathrm{p}<0.01$.

Hypotheses 5 and 6 predicted that information exchange and team creative problem solving would both have a positive effect on team creativity outcomes. As Table 4 illustrates, there was no support in the data for significant effects, and thus no support for either hypothesis.

Table 5. Regression: team creativity as dependent variable

\begin{tabular}{|c|c|c|c|c|c|c|}
\hline \multicolumn{7}{|c|}{ Std. Beta coefficient (std. error) } \\
\hline & \multicolumn{2}{|c|}{ Model 1} & \multicolumn{2}{|c|}{ Model 2} & \multicolumn{2}{|c|}{ Model 3} \\
\hline Task conflict & $-.42 *$ & $(.10)$ & & & $-.63 *$ & $(.19)$ \\
\hline Relationship conflict & & & -.28 & $(.08)$ & .31 & $(.14)$ \\
\hline Adjusted $\mathrm{R}^{2}$ & & .15 & & .05 & & .15 \\
\hline Regression F & & $6.59^{*}$ & & 2.56 & & $3.77 *$ \\
\hline DF & 31.1 & & 31.1 & & 30.2 & \\
\hline
\end{tabular}

Note. $\uparrow-\mathrm{p}<0.10 *-\mathrm{p}<0.05 * *-\mathrm{p}<0.01$

Hypotheses 7 predicted that task conflict would have a negative effect on team creativity outcomes. Models 1 and 3 in Table 5 illustrate that task conflict has a significant negative effect on team creativity outcomes. Thus, hypothesis 7 was supported.

Hypothesis 8 predicted that relationship conflict would have a negative effect on team creativity outcomes. As Models 2 and 3 in Table 5 illustrate, there was no significant effect, and hypothesis 8 was not supported.

Due to the lack of detectable effects between the process variables and the team creativity outcome variable, the implied mediation is clearly not supportable in either case, and thus we did not perform further formal mediation tests.

\section{Discussion}

In the context of the burgeoning research on team creativity, we attempted to extend the understanding of how conflict relates to team creativity. We attempted to resolve theoretical discrepancies inherent in the literature in two ways: First, by looking at the effects of conflict on team creative processes separately from team creative outcomes, particularly by looking at the two creative process variables most often implicated to explain the effects of conflict on creativity, namely information exchange and team creative problem solving; and, second, by testing the hypothesized relationships between conflict, creative processes, and creative outcomes using multi-wave longitudinal data. Our findings suggest that while relationship conflict does have a negative effect on team creative processes (both information exchange and team creative problem solving), task conflict does not. The relationship between task conflict and each of the team creative process variables was non-significant. In contrast, it was only task conflict, and not relationship conflict, that had an effect on creative outcomes. Most surprisingly, the negative relationship between task conflict and team creative outcomes was not mediated by team creative processes.

That relationship conflict, but not task conflict, was related to team creative processes was contrary to some of our hypotheses, but not necessarily surprising. Within the conflict literature, there have been two competing views on the nature and the effect of conflict on group processes. The debate centers primarily on the nature of the effects of task conflict, and less so relationship conflict. On the one hand, conflict was envisioned as disruptive and stressful, with detrimental effects on team functioning and team outcomes. On the other hand, conflict was envisioned as being functional and stimulating, with positive effects on team functioning and team outcomes for certain types of conflict (task, but not relationship). Given the cognitive demands of creative 
problem solving, and the sensitivity of information exchange to healthy team relationships, we believe that the conflict as disruption model is a more plausible expectation for how conflict might affect team creative processes; hence we predicted negative team creative process effects for both types of conflict.

Our findings support our point of view for relationship conflict, but not for task conflict. Unfortunately, the non-significance of the effects of task conflict on both information exchange and team creative problem solving leaves the question of disruptive or functional somewhat open-ended. There are methodological issues that could potentially explain the null findings (see limitations), but there is also the possibility that moderators are at work. While relationship conflict is simply disruptive, task conflict's disruption could be dependent on other group processes, or perhaps the overall health of the interpersonal relationship between team members.

With regard to outcomes, our results suggest exactly the opposite. The fact that we found a negative relationship between task conflict and team creative outcomes supports the view of task conflict as disruptive. Interestingly, this disruption is not explained by task conflict's effects on team creative processes (as noted above, task conflict was not found to have a significant effect on team creative processes). This suggests that the traditional arguments for how conflict might undermine creativity are not broad enough. This further suggests that it may be worthy to pursue other creativity-relevant processes that may be undermined by task conflict.

A more surprising finding to us was the lack of a relationship between team creative processes and creative outcomes. While engagement in team creative processes can be argued to be a necessary, but not sufficient, condition for generating creative outcomes, it was still surprising to not find this relationship significant. It could be argued that there are other components (to borrow the term from Amabile's (1988) social psychological theory of creativity at the individual level) that must be present for creative problem solving to yield a creative solution. Of particular interest may be the role of team domain-specific knowledge, or motivation to be creative. It may also be that the team generated plenty of variety of ideas, but failed at the stage of selection (using Simonton's view of the creative process as variation and selection). This finding perhaps raises more questions than it answers.

\subsection{Theoretical Implications}

We are breaking new ground by opening the black box of "process" in the traditional "input-process-output" (McGrath, 1984) model, and exploring for the first time how the process variables of information exchange and team creative problem solving are involved in the relationship between intra-team conflict and team creativity. These findings are important because our current understanding of creativity, and its antecedents in teams, is still quite unclear, and particularly so with respect to the effects of conflict. While we may not have answered all of the questions in this study, we have begun to answer them, and our research has allowed us to pose additional questions that will hopefully move research forward.

Overall, the implications for research include a variety of things. First, a greater focus may be needed on the possible mediators involved in the effect of intra-team conflict on team creativity. This study raises as many questions as it answers, and casts some doubt over the belief that team creative problem solving is directly related to creativity outcomes, for example. Second, the implications include a search for additional moderators. The lack of effects between the process variables and the outcome measure may be a result of disordinal interactions, and plausible moderators should be explored and tested empirically, before throwing the baby out with the bathwater. Additionally, the question of moderation is particularly relevant to the lack of a direct effect of relationship conflict on team creativity outcomes as well, given the expectations as well as the significant effects for task conflict.

\subsection{Practical Implications}

The study has some cautionary practical implications, partly as a result of what it doesn't find. Given the absence of any significant effects of the expected process variables on creative outcomes-in the only study to date that has attempted to empirically establish them - it may be premature to assume that the causal links even exist. Thus, the managerial implication may be to be cautious about expectations that managing the team creative problem solving or information exchange processes will invariably result in good creative outcomes for the team. Furthermore, the inconsistency between the task and relationship findings may be worrisome for managers and organizations that rely heavily on teams, because it echoes the findings of DeDreu and Weingart (2003) in suggesting that managers need to be very hesitant to accept the conventional wisdom that task conflict can have a variety of beneficial positive effects on team outcomes.

\subsection{Limitations and Boundary Conditions}

A restriction of range may exist in the data, in that levels of conflict were relatively low. However, such a 
restriction of range would normally create a problem for analysis and causal inference, not for generalizability. In other words, lower variance makes for somewhat more conservative analyses, and the fact that effects were found, especially given the low power, suggests relatively robust effects.

In terms of generalizability, the composition of the teams may be a limiting factor. On the one hand, while the teams were quite diverse (in terms of national origin, gender, education, etc.), on the other hand, they could also be perceived as fairly homogenous, since all team members were MBA students similar in age and at the same university. The specific context of our study may also limit the generalizability of the findings somewhat. While the almost quasi-experimental nature of our study, with identical teams, identical tasks, clear performance measures, zero turnover, etc. all contributed to greater statistical conclusion validity, it also potentially undermined external validity. Thus, our study did take place in a somewhat idealized context, and the results should be considered accordingly.

Another potential limitation is that we did not consider possible moderators of the relationship between task or relationship conflict and creativity. DeDreu \& Weingart (2003) noted that the negative effects of conflict may be ameliorated by aspects of team norms, and factors such as openness or psychological safety. Our model is a good starting point, but it is certainly not intended to be a comprehensive model that addresses all nuances of these relationships. In addition to exploring moderators in the future, there are undoubtedly more specific micro-mediators as well. They include norm development within the team, or a variety of team dynamics. Such detailed causal micro-mediators are clearly important avenues for a detailed understanding of these effects. In addition, more qualitative observation would also yield a greater understanding of the processes and effects found in this study.

In summary, we have broken new ground in exploring process variables in the relationship between intra-team conflict and team creativity outcomes. Our findings suggest that relationship conflict has detrimental effects only on team creative processes, while task conflict has detrimental effects only on team creative outcomes. While these effects are meaningful and important, our findings leave some interesting questions unanswered and ripe for future research.

\section{References}

Amabile, T. M. (1996). Creativity in context: Update to the social psychology of creativity. Boulder, CO: Westview Press.

Amason, A. C. (1996). Distinguishing the effects of functional and dysfunctional conflict on strategic decision making: Resolving a paradox for top management teams. Academy of Management Journal, 39, 123-148. http://dx.doi.org/10.2307/256633

Bales, R. E. (1951). Interaction process analysis. Cambridge, MA: Addison-Wesley.

Befar, K., \& Thompson, L. (in press). Conflict within and between organizational groups: Functional, dysfunctional, and quasi-functional perspectives. In L. Thompson \& K. Befar (Eds.), Conflict in teams. Evanston, IL: Northwestern University Press.

Bunderson, J. S., \& Sutcliffe, K. M. (2002). Comparing alternative conceptualizations of functional diversity in management teams: Process and performance effects. Academy of Management Journal, 45(5), 875-893. http://dx.doi.org/10.2307/3069319

Carnevale, P. A., \& Probst, T. N. (1998). Social values and social conflict in creative problem solving and categorization. Journal of Personality and Social Psychology, 74, 1300-1309. http://dx.doi.org/10.1037/0022-3514.74.5.1300

Cohen, J., \& Cohen, P. (1983). Applied multiple regression/correlation analysis for the behavioral sciences (2nd ed.). Hillsdale, NJ: Erlbaum.

De Dreu, C. K. W., \& Weingart, L. R. (2003). Task versus relationship conflict, team performance, and team member satisfaction: A meta-analysis. Journal of Applied Psychology, 88, 741-749. http://dx.doi.org/10.1037/0021-9010.88.4.741

Devine, D. J. (1999). Effects of cognitive ability, task knowledge, information sharing, and conflict on group decision-making effectiveness. Small Group Research, 30, 608-634. http://dx.doi.org/10.1177/104649649903000506

George, J. M., \& James, L. R. (1993). Personality, affect, and behavior in groups revisited: Comment on aggregation, levels of analysis, and a recent application of within and between analysis. Journal of Applied Psychology, 78(5), 798-804. http://dx.doi.org/10.1037/0021-9010.78.5.798 
Gilson, L. L., \& Shalley, C. E. (2004). A little creativity goes a long way: An examination of teams' engagement in creative processes. Journal of Management, 30, 45-470. http://dx.doi.org/10.1016/j.jm.2003.07.001

Henry, R. (1995). Improving group judgment accuracy: Information sharing and determining the best member. Organizational Behavior and Human Decision Processes, 62, 190-197. http://dx.doi.org/10.1006/obhd.1995.1042

Ilgen, D. R., Hollenbeck, J. R., Johnson, M., \& Jundt, D. (2005). Teams in organizations: From input-process-output models to IMOI models. Annual Review of Psychology, 56, 517-543. http://dx.doi.org/10.1146/annurev.psych.56.091103.070250

James, L. R., Demaree, R. G., \& Wolf, G. (1993). $\mathrm{R}_{\mathrm{wg}}$ : An assessment of within-group interrater agreement. Journal of Applied Psychology, 78(2), 306-309. http://dx.doi.org/10.1037/0021-9010.78.2.306

Jehn, K., \& Mannix, E. (2001). The dynamic nature of conflict: A longitudinal study of intragroup conflict and group performance. Academy of Management Journal, 44, 238-251. http://dx.doi.org/10.2307/3069453

Jehn, K. A. (1995). A multimethod examination of the benefits and detriments of intragroup conflict. Administrative Science Quarterly, 40, 256-282. http://dx.doi.org/10.2307/2393638

Jehn, K., \& Bendersky, C. (2003). Intragroup conflict in organizations: A contingency perspective on the conflict-outcome relationship. Research in Organizational Behavior, 24, 187-242. http://dx.doi.org/10.1016/S0191-3085(03)25005-X

Kanter, R. M. (1988). When a thousand flowers bloom: Structural, collective, and social conditions for innovation in organizations. In B. Staw \& L. L. Cummings (Eds.), Research in organizational behavior (Vol. 10, pp. 169-211). Greenwich CT: JAI Press.

Li, J., \& Hambrick, D. C. (2005). Factional groups: A new vantage on demographic faultlines, conflict and disintegration in work teams. Academy of Management Journal, 48(5), 794-813. http://dx.doi.org/10.5465/AMJ.2005.18803923

Mumford, M. D. (2003). Where have we been, where are we going? Taking stock in creativity research. Creativity Research Journal, 15, 107-120. http://dx.doi.org/10.1080/10400419.2003.9651403

Nemeth, C. J., Personnaz, B., Personnaz, M., \& Goncalo, J. A. (2004). The liberating role of conflict in group creativity: A study in two countries. European Journal of Social Psychology, 34, 365-374. http://dx.doi.org/10.1002/ejsp.210

Paulus, P. B., Brown, V., \& Ortega, A. H. (1999). Group creativity. In R. E. Purser \& A. Montuori (Eds.), Social creativity (Vol. 2, pp. 151-176). Cresskill, NJ: Hampton Press.

Peterson, R. S., \& Befar, K. J. (2003). The dynamic relationship between performance feedback, trust and conflict in groups: A longitudinal study. Organizational Behavior and Human Decision Processes, 92(1-2), 102-112. http://dx.doi.org/10.1016/S0749-5978(03)00090-6

Shalley, C. E., Zhou, J., \& Oldham, G. R. (2004). The effects of personal and contextual characteristics on creativity: Where should we go from here? Journal of Management, 6, 642-662.

Simonton, D. K. (1999). Creativity and genius. In L. Pervin \& O. John (Eds.), Handbook of personality theory and research (2nd ed., pp. 629-652). New York: Guilford Press.

Singer, J. D., \& Willett, J. B. (2003). Applied longitudinal analysis: Modeling change and event occurrence. New York, NY: Oxford University Press. http://dx.doi.org/10.1093/acprof:oso/9780195152968.001.0001

Stasser, G. (1992). Information salience and the discovery of hidden profiles by decision-making groups: A "thought experiment." Organizational Behavior and Human Decision Processes, 52, 156-181. http://dx.doi.org/10.1016/0749-5978(92)90049-D

Taggar, S. (2002). Individual creativity and group ability to utilize individual creative resources: A multilevel model. Academy of Management Journal, 45, 315-330. http://dx.doi.org/10.2307/3069349

Tekleab, A. G., Takeuchi, R., \& Taylor, M. S. (2005). Extending the chain of relationships among organizational justice, social exchange, and employee reactions: The role of contract violations. Academy of Management Journal, 48, 146-157. http://dx.doi.org/10.5465/AMJ.2005.15993162

Wageman, R. (2001). How leaders foster self-managing team effectiveness: Design choices versus hands-on coaching. Organization Science, 12, 559-577.

Wall, V. D., \& Nolan, L. L. (1986). Perceptions of inequity, satisfaction and conflict in task-oriented groups. 
Human Relations, 39(11), 1033-1051. http://dx.doi.org/10.1177/001872678603901106

West, M. A., \& Farr, J. L. (1990). Innovation at work. In W. West \& J. Farr (Eds.), Innovation and creativity at work: Psychological and organizational strategies. Chichester, England Wiley.

Woodman, R. W., Sawyer, J. E., \& Griffin, R. W. (1993). Toward a theory of organizational creativity. Academy of Management Review, 18, 293-321.

\section{Note}

Note 1. Factor analysis results for the measurement scales are available from the first author.

\section{Copyrights}

Copyright for this article is retained by the author(s), with first publication rights granted to the journal.

This is an open-access article distributed under the terms and conditions of the Creative Commons Attribution license (http://creativecommons.org/licenses/by/3.0/). 